\title{
Autosomal dominant spastic paraplegia type 31
}

INSERM

\section{Source}

INSERM. (1999). Orphanet: an online rare disease and orphan drug data base. Autosomal dominant spastic paraplegia type 31. ORPHA:101011

Autosomal dominant spastic paraplegia type 31 (SPG31) is a type of hereditary spastic paraplegia usually characterized by a pure phenotype of proximal weakness of the lower extremities with spastic gait and brisk reflexes, with a bimodal age of onset of either childhood or adulthood ( $>30$ years). In some cases, it can present as a complex phenotype with additional associated manifestations including peripheral neuropathy, bulbar palsy (with dysarthria and dysphagia), distal amyotrophy, and impaired distal vibration sense. 